\title{
Erratum to: Aerosol-Transmitted Infections - a New Consideration for Public Health and Infection Control Teams
}

Julian W. Tang, MA, PhD, MRCP, FRCPath, FHKCPath, FHKAM ${ }^{1, *}$

Peter Wilson, MD, FRCP, FRCPath ${ }^{2}$

Nandini Shetty, MD, FRCPath ${ }^{2}$

Catherine J. Noakes, PhD, CEng, FIMechE, FIHEEM ${ }^{3}$

\author{
Address \\ ${ }^{*}{ }^{1}$ Clinical Microbiology, Leicester Royal Infirmary, University Hospitals Leicester, \\ Leicester NHS Trust, Leicester, LE1 5WW, UK \\ Email: jwtang49@hotmail.com \\ ${ }^{2}$ Clinical Microbiology, University College London Hospitals NHS Trust, London, UK \\ ${ }^{3}$ Institute for Public Health and Environmental Engineering, School of Civil \\ Engineering, University of Leeds, Leeds, UK
}

Published online: 9 September 2015

(C) Springer Science+Business Media New York 2015

The online version of the original article can be found at http://dx.doi.org/ 10.1007/s40506-015-0057-1.

\section{Erratum to: Curr Treat Options Infect Dis \\ DOI 10.1007/s40506-015-0057-1}

In the citation for Table 1, "By permission of Oxford University Press (www.oup.com)" should be included, so that the full table legend and citation reads as follows:

Table 1. The basic reproductive number $\left(\mathrm{R}_{\mathrm{o}}\right)$ for some common infectious agents where the airborne transmission route is significant (By permission of Oxford University Press (www.oup.com), derived from Anderson and May [1991] [88]). 